International Journal of Soft Computing 6 (5-6): 216-223, 2011

ISSN: $1816-9503$

(C) Medwell Journals, 2011

\title{
The Generalized Projective Synchronization of Hyperchaotic Lorenz and Hyperchaotic Qi Systems via Active Control
}

\author{
${ }^{1} \mathrm{P}$. Sarasu and ${ }^{2} \mathrm{~V}$. Sundarapandian \\ ${ }^{1}$ Faculty of Computer Science and Engineering, ${ }^{2}$ Research and Development Centre, \\ Vel Tech Dr. RR and Dr. SR Technical University, Avadi, 600-062 Chennai, India
}

\begin{abstract}
This study investigates the active controller design for Generalized Projective Synchronization (GPS) of identical Hyperchaotic Lorenz Systems, identical Hyperchaotic Qi Systems and Non-Identical Hyperchaotic Lorenz and Hyperchaotic Qi Systems. The GPS synchronization results for the Hyperchaotic Systems have been derived using the active control method and established using Lyapunov Stability theory. Since, the Lyapunov exponents are not required for these calculations, the active control method is a very effective and convenient method for achieving Generalized Projective Synchronization (GPS) of the Hyperchaotic Systems addressed in this study. Numerical simulations are shown to demonstrate the effectiveness of the synchronization results derived in this study for the Hyperchaotic Systems.
\end{abstract}

Key words: Active control, hyperchaos, generalized projective synchronization, Hyperchaotic Lorenz System, Hyperchaotic Qi System, Hyperchaotic Systems

\section{INTRODUCTION}

Chaotic Systems are Nonlinear Dynamical Systems which possess some special features such as being extremely sensitive to small variations of initial conditions having bounded trajectories in the phase space and so on. The sensitive nature of Chaotic Systems is commonly called as the butterfly effect (Alligood et al., 1997). The chaos phenomenon was first observed in weather models by Lorenz (1963).

Hyperchaotic System is usually defined as a Chaotic System having more than one positive Lyapunov exponent. Since, Hyperchaotic System has the characteristics of high capacity, high security and high efficiency, it has the potential of broad applications in nonlinear circuits, neural networks, lasers, secure communications, biological systems and so on. The hyperchaos phenomenon was first observed by Rossler (1979).

Synchronization of Chaotic Systems is a phenomenon that may occur when two or more chaotic oscillators are coupled or when a chaotic oscillator drives another chaotic oscillator. Because of the butterfly effect which causes the exponential divergence of the trajectories of two identical chaotic systems started with nearly the same initial conditions, synchronizing two Chaotic Systems is seemingly a very challenging research problem.

In most of the chaos synchronization approaches, the master-slave or drive-response formalism is used. If a particular Chaotic System is called a Master or Drive System and another Chaotic System is called a Slave or Response System, then the idea of chaos synchronization is to use the output of the Master System to control the Slave System so that the output of the Slave System tracks the output of the Master System asymptotically.

Chaos is an interesting nonlinear phenomenon and it has been intensively and extensively studied in the last three decades. Chaos theory has wide applications in several fields such as physical systems (Lakshmanan and Murali, 1996), chemical systems (Han et al., 1995), ecological systems (Blasius et al., 1999), secure communications (Cuomo et al., 1993; Kocarev and Parlitz, 1995), etc.

The seminal work by Pecora and Carroll (1990) is followed by a variety of impressive approaches for chaos synchronization such as the Sampled-Data Feedback Synchronization method (Yang and Chua, 1999), the OGY method (Ott et al., 1990), the time-delay feedback method (Park and Kwon, 2003), the active control method (Ho and Hung, 2002; Sundarapandian, 2011a, b), the adaptive control method (Chen and Lu, 2002; Sundarapandian, $2011 \mathrm{c}, \mathrm{d}$ ), the backstepping method (Mascolo and Grassi, 1999; Tan et al., 2003), the sliding mode control method (Utkin, 1977; Sundarapandian, 2011e) and others. In generalized projective synchronization (Zhou et al., 2010), the chaotic systems can synchronize up to a constant scaling matrix. Complete synchronization (Sundarapandian, 2011f), anti-synchronization

Corresponding Author: P. Sarasu, Faculty of Computer Science and Engineering, Vel Tech Dr. RR and Dr. SR Technical University, Avadi, 600-062 Chennai, India 
(Sundarapandian, 2011g), hybrid synchronization (Sundarapandian, 2011a-g), projective synchronization (Mainieri and Rehacek, 1999) and generalized synchronization (Wang and Guan, 2006) are special cases of the generalized projective synchronization. The Generalized Projective Synchronization (GPS) has applications in secure communications.

This study addresses the design of active controllers for the Generalized Projective Synchronization (GPS) of identical hyperchaotic Lorenz Systems (Jia, 2007), identical Hyperchaotic Qi Systems (Chen et al., 2007) and non-identical Hyperchaotic Lorenz and Hyperchaotic Qi Systems. The synchronization results derived in this paper are established using the Lyapunov Stability theory (Hahn, 1967).

\section{PROBLEM STATEMENT AND METHODOLOGY}

Consider the Chaotic System described by the dynamics:

$$
\dot{x}=A x+f(x)
$$

where, $x \in R^{n}$ is the state of the system, $A$ is the $n x$ matrix of the system parameters and $\mathrm{f}: \mathrm{R}^{\mathrm{n}} \rightarrow \mathrm{R}^{\mathrm{n}}$ is the nonlinear part of the system. Researchers consider the system (1) as the Master or Drive System. As the Slave or Response System, we consider the following Chaotic System described by the dynamics:

$$
\dot{y}=B y+g(y)+u
$$

where, $y \in R^{n}$ is the state of the system, $B$ is the $n x n$ real matrix of the system parameters, $g: R^{n} \rightarrow R^{n}$ is the nonlinear part of the system and $u \in R^{n}$ is the controller of the slave system.

If $\mathrm{A}=\mathrm{B}$ and $\mathrm{f}=\mathrm{g}$ then $\mathrm{x}$ and $\mathrm{y}$ are the states of two identical Chaotic Systems. If $\mathrm{A} \neq \mathrm{B}$ or $\mathrm{f} \neq \mathrm{g}$ then $\mathrm{x}$ and $\mathrm{y}$ are the states of two different Chaotic Systems.

In the active control approach, researchers design a feedback controller $\mathrm{u}$ which achieves the Generalized Projective Synchronization (GPS) between the states of the master system (1) and the slave system (2) for all initial conditions $\mathrm{x}(0), \mathrm{z}(0) \in \mathrm{R}^{\mathrm{n}}$. For the GPS of the systems (1) and (2), the synchronization error is defined as:

Where:

$$
\mathrm{e}=\mathrm{y}-\mathrm{Mx}
$$

$$
\mathrm{M}=\left[\begin{array}{cccc}
\alpha_{1} & 0 & \cdots & 0 \\
0 & \alpha_{2} & \cdots & 0 \\
\vdots & \vdots & \ddots & \vdots \\
0 & 0 & \cdots & \alpha_{\mathrm{n}}
\end{array}\right]
$$

In other words, we have:

$$
\mathrm{e}_{\mathrm{i}}=\mathrm{y}_{\mathrm{i}}-\alpha_{\mathrm{i}} \mathrm{x}_{\mathrm{i}},(\mathrm{i}=1,2, \ldots, \mathrm{n})
$$

From Eq. 1-3, the error dynamics is easily obtained as:

$$
\dot{e}=B y-M A x+g(y)-M f(x)+u
$$

The aim of GPS is to find a feedback controller $u$ so that:

$$
\lim _{t \rightarrow \infty}\|e(t)\|=0 \text { forall } e(0) \in R^{n}
$$

Thus, the problem of Generalized Projective Synchronization (GPS) between the Master System (1) and Slave System (2) can be translated into a problem of how to realize the asymptotic stabilization of the system (6). Hence, the objective is to design an active controller $\mathrm{u}$ for stabilizing the Error Dynamical System (6) at the origin. Researchers take as a candidate Lyapunov function:

$$
\mathrm{V}(\mathrm{e})=\mathrm{e}^{\mathrm{T}} \mathrm{Pe}
$$

where, $\mathrm{P}$ is a positive definite matrix. $\mathrm{V}: \mathrm{R}^{\mathrm{n}} \rightarrow \mathrm{R}$ is a positive definite function by construction. We assume that the parameters of the Master and Slave System are known and that the states of both systems (1) and (2) are measurable. If we find a feedback controller u so that:

$$
\dot{V}(e)=-e^{T} Q e
$$

where, $Q$ is a positive definite matrix, then $\dot{V}: R^{n} \rightarrow R$ is a negative definite function. Thus, by Lyapunov Stability theory (Hahn, 1967), the error dynamics (6) is globally exponentially stable and hence the condition (7) will be satisfied. Hence, GPS is achieved between the states of the Master System (1) and the Slave System (2).

\section{SYSTEMS DESCRIPTION}

The hyperchaotic Lorenz System (Jia, 2007) is described by the dynamics:

$$
\begin{aligned}
& \dot{\mathrm{x}}_{1}=\mathrm{a}\left(\mathrm{x}_{2}-\mathrm{x}_{1}\right)+\mathrm{x}_{4} \\
& \dot{\mathrm{x}}_{2}=-\mathrm{x}_{1} \mathrm{x}_{3}+\mathrm{cx}_{1}-\mathrm{x}_{2} \\
& \dot{\mathrm{x}}_{3}=\mathrm{x}_{1} \mathrm{x}_{2}-\mathrm{bx}_{3} \\
& \dot{\mathrm{x}}_{4}=-\mathrm{x}_{1} \mathrm{x}_{3}+\mathrm{dx}_{4}
\end{aligned}
$$

where, $x_{i}$ are the state variables and a-d are positive, constant parameters of the system. The system (10) is hyperchaotic when the parameter values are chosen as: 

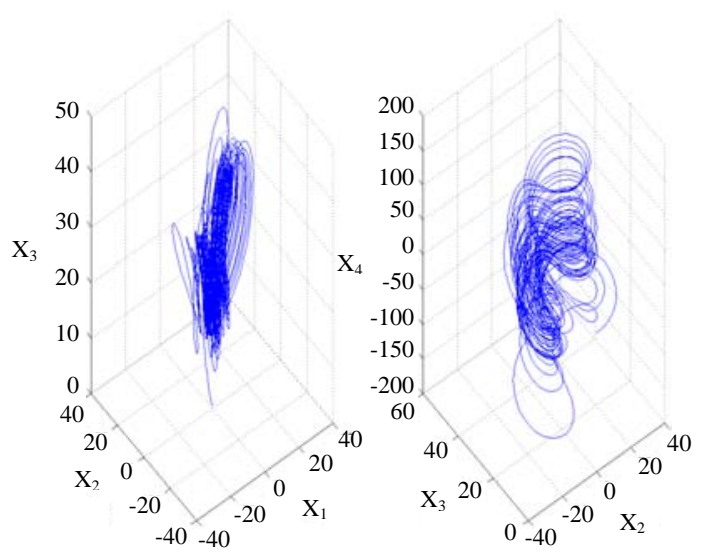

Fig. 1: Phase portrait of the Hyperchaotic Lorenz System

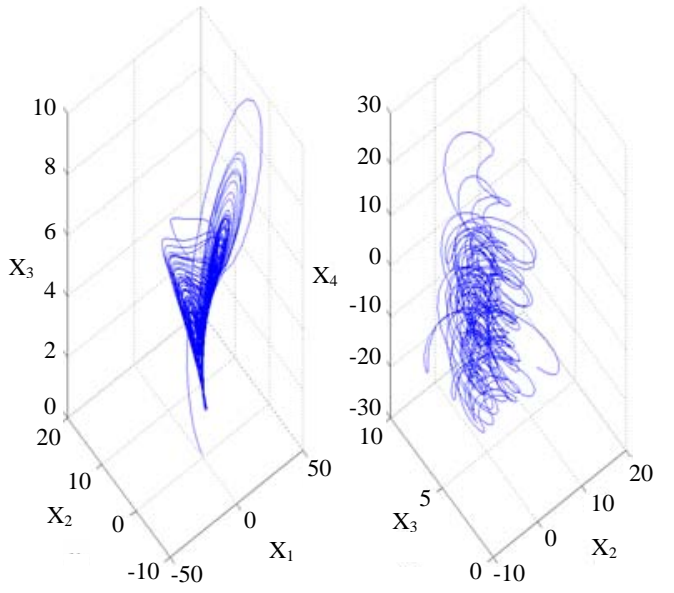

Fig. 2: Phase portrait of the Hyperchaotic Qi System

$$
a=10, b=8 / 3, c=28, d=1.3
$$

Figure 1 shows the phase portrait of the hyperchaotic Lorenz System (10). The Hyperchaotic Qi System (Chen et al., 2007) is described by the dynamics:

$$
\begin{aligned}
& \dot{\mathrm{x}}_{1}=\mathrm{p}\left(\mathrm{x}_{2}-\mathrm{x}_{1}\right)+\varepsilon \mathrm{x}_{2} \mathrm{x}_{3} \\
& \dot{\mathrm{x}}_{2}=\mathrm{rx}_{1}-\mathrm{sx}_{1} \mathrm{x}_{3}+\mathrm{x}_{2}+\mathrm{x}_{4} \\
& \dot{\mathrm{x}}_{3}=\mathrm{x}_{1} \mathrm{x}_{2}-\mathrm{qx}_{3} \\
& \dot{\mathrm{x}}_{4}=-\lambda \mathrm{x}_{2}
\end{aligned}
$$

where, $\mathrm{x}_{\mathrm{i}}(\mathrm{i}=1-4)$ are the state variables and $\mathrm{p}-\mathrm{s}, \varepsilon, \lambda$ are positive, constant parameters of the system. The system (11) is hyperchaotic when the parameter values are chosen as:

$$
\mathrm{p}=35, \mathrm{q}=4.9, \mathrm{r}=25, \mathrm{~s}=5, \varepsilon=35, \lambda=22
$$

Figure 2 shows the phase portrait of the hyperchaotic Qi System (11).

\section{GPS OF IDENTICAL HYPERCHAOTIC LORENZ SYSTEMS}

Theoretical results: Researchers derive results for the Generalized Projective Synchronization (GPS) of identical hyperchaotic Lorenz systems ( $\mathrm{Jia}, 2007$ ). Thus, the master system is described by the Hyperchaotic Lorenz dynamics:

$$
\begin{aligned}
& \dot{\mathrm{x}}_{1}=\mathrm{a}\left(\mathrm{x}_{2}-\mathrm{x}_{1}\right)+\mathrm{x}_{4} \\
& \dot{\mathrm{x}}_{2}=-\mathrm{x}_{1} \mathrm{x}_{3}+\mathrm{cx}_{1}-\mathrm{x}_{2} \\
& \dot{\mathrm{x}}_{3}=\mathrm{x}_{1} \mathrm{x}_{2}-\mathrm{bx}_{3} \\
& \dot{\mathrm{x}}_{4}=-\mathrm{x}_{1} \mathrm{x}_{3}+\mathrm{dx}_{4}
\end{aligned}
$$

Where:

$\mathrm{x}_{1}-\mathrm{x}_{4}=$ The state variables

$\mathrm{a}-\mathrm{d}=$ Constant, positive parameters of the system

Also, the Slave System is described by the controlled Hyperchaotic Lorenz dynamics:

$$
\begin{aligned}
& \dot{\mathrm{y}}_{1}=\mathrm{a}\left(\mathrm{y}_{2}-\mathrm{y}_{1}\right)+\mathrm{y}_{4}+\mathrm{u}_{1} \\
& \dot{\mathrm{y}}_{2}=-\mathrm{y}_{1} \mathrm{y}_{3}+\mathrm{cy}_{1}-\mathrm{y}_{2}+\mathrm{u}_{2} \\
& \dot{\mathrm{y}}_{3}=\mathrm{y}_{1} \mathrm{y}_{2}-\mathrm{by}_{3}+\mathrm{u}_{3} \\
& \dot{\mathrm{y}}_{4}=-\mathrm{y}_{1} \mathrm{y}_{3}+\mathrm{dy}_{4}+\mathrm{u}_{4}
\end{aligned}
$$

Where:

$\mathrm{y}_{1}-\mathrm{y}_{4}=$ The state variables

$\mathrm{u}_{1}-\mathrm{u}_{4}=$ The active controllers of the system

For the GPS of the Hyperchaotic Systems (12) and (13), the synchronization error is defined as:

$$
e_{i}=y_{i}-\alpha_{i} x, \quad(i=1-4)
$$

where, the scales $\alpha_{1}-\alpha_{4}$ are real constants. A simple calculation yields the error dynamics:

$$
\begin{aligned}
& \dot{\mathrm{e}}_{1}=a\left(\mathrm{y}_{2}-\mathrm{y}_{1}\right)+\mathrm{y}_{4}-\alpha_{1}\left[\mathrm{a}\left(\mathrm{x}_{2}-\mathrm{x}_{1}\right)+\mathrm{x}_{4}\right]+\mathrm{u}_{1} \\
& \dot{\mathrm{e}}_{2}=-\mathrm{y}_{1} \mathrm{y}_{3}+\mathrm{cy}_{1}-\mathrm{y}_{2}-\alpha_{2}\left[-\mathrm{x}_{1} \mathrm{x}_{3}+\mathrm{cx}_{1}-\mathrm{x}_{2}\right]+\mathrm{u}_{2} \\
& \dot{\mathrm{e}}_{3}=\mathrm{y}_{1} \mathrm{y}_{2}-b \mathrm{y}_{3}-\alpha_{3}\left[\mathrm{x}_{1} \mathrm{x}_{2}-\mathrm{bx}_{3}\right]+\mathrm{u}_{3} \\
& \dot{\mathrm{e}}_{4}=-\mathrm{y}_{1} \mathrm{y}_{3}+\mathrm{dy}_{4}-\alpha_{4}\left[-\mathrm{x}_{1} \mathrm{x}_{3}+\mathrm{dx}_{4}\right]+\mathrm{u}_{4}
\end{aligned}
$$
by:

We consider the active nonlinear controller defined

$$
\begin{aligned}
& \mathrm{u}_{1}=-\mathrm{a}\left(\mathrm{y}_{2}-\mathrm{y}_{1}\right)-\mathrm{y}_{4}+\alpha_{1}\left[\mathrm{a}\left(\mathrm{x}_{2}-\mathrm{x}_{1}\right)+\mathrm{x}_{4}\right]-\mathrm{k}_{1} \mathrm{e}_{1} \\
& \mathrm{u}_{2}=\mathrm{y}_{1} \mathrm{y}_{3}-\mathrm{cy}_{1}+\mathrm{y}_{2}+\alpha_{2}\left[-\mathrm{x}_{1} \mathrm{x}_{3}+\mathrm{cx}_{1}-\mathrm{x}_{2}\right]-\mathrm{k}_{2} \mathrm{e}_{2} \\
& \mathrm{u}_{3}=-\mathrm{y}_{1} \mathrm{y}_{2}+\mathrm{by}_{3}+\alpha_{3}\left[\mathrm{x}_{1} \mathrm{x}_{2}-\mathrm{bx}_{3}\right]-\mathrm{k}_{3} \mathrm{e}_{3} \\
& \mathrm{u}_{4}=\mathrm{y}_{1} \mathrm{y}_{3}-d \mathrm{y}_{4}+\alpha_{4}\left[-\mathrm{x}_{1} \mathrm{x}_{3}+d \mathrm{x}_{4}\right]-\mathrm{k}_{4} \mathrm{e}_{4}
\end{aligned}
$$

where, the gains $k_{1}-k_{4}$ are positive constants. Substitution of (16) into (15) yields the closed-loop error dynamics: 
Int. J. Soft Comput., 6 (5-6): 216-223, 2011

$$
\begin{array}{ll}
\dot{\mathrm{e}}_{1}=-\mathrm{k}_{1} \mathrm{e}_{1} \quad, \quad \dot{\mathrm{e}}_{2}=-\mathrm{k}_{2} \mathrm{e}_{2} \\
\dot{\mathrm{e}}_{3}=-\mathrm{k}_{3} \mathrm{e}_{3} \quad, \quad \dot{\mathrm{e}}_{4}=-\mathrm{k}_{4} \mathrm{e}_{4}
\end{array}
$$

Theorem 1: The active controller (16) achieves Generalized Projective Synchronization (GPS) between the identical Hyperchaotic Lorenz Systems (12) and (13) globally and exponentially.

Proof: We prove this result using the Lyapunov Stability theory. We consider the Quadratic Lyapunov function defined by:

$$
V(e)=\frac{1}{2} e^{T} e=\frac{1}{2}\left(e_{1}^{2}+e_{2}^{2}+e_{3}^{2}+e_{4}^{2}\right)
$$

Which is positive definite on $\mathrm{R}^{4}$. Differentiating (18) along the trajectories of the system (17), we get:

$$
\dot{\mathrm{V}}(\mathrm{e})=-\mathrm{k}_{1} \mathrm{e}_{1}^{2}-\mathrm{k}_{2} \mathrm{e}_{2}^{2}-\mathrm{k}_{3} \mathrm{e}_{3}^{2}-\mathrm{k}_{4} \mathrm{e}_{4}^{2}
$$

Which is a negative definite function on $\mathrm{R}^{4}$. Thus, by the Lyapunov Stability theory (Hahn, 1967), it follows that the error dynamics (17) is globally exponentially stable. This completes the proof.

Numerical results: For the numerical simulations, the fourth-order Runge-Kutta method with time step $h=10^{-8}$ is used to solve the two systems of differential Eq. 12 and 13 with the active controller (16). The parameters of the identical Hyperchaotic Lorenz Systems are chosen as:

$$
a=10, b=8 / 3, c=28, d=1.3
$$

The initial values of the master system (12) are chosen as:

$$
x_{1}(0)=5, x_{2}(0)=11, x_{3}(0)=28, x_{4}(0)=20
$$

The initial values of the slave system (13) are chosen as:

$$
\mathrm{y}_{1}(0)=18, \mathrm{y}_{2}(0)=22, \mathrm{y}_{3}(0)=7, \mathrm{y}_{4}(0)=30
$$

The GPS scales $\alpha_{\mathrm{i}}$ are taken as:

$$
\alpha_{1}=6.2, \alpha_{2}=2.3, \alpha_{3}=3.7, \alpha_{4}=5.6
$$

We take the state feedback gains as:

$$
\mathrm{k}_{1}=4, \mathrm{k}_{2}=4, \mathrm{k}_{3}=4, \mathrm{k}_{4}=4
$$

Figure 3 shows the GPS between the identical Hyperchaotic Lorenz Systems (12) and (13). Figure 4 shows the time history of the error states $\mathrm{e}_{1}-\mathrm{e}_{4}$.

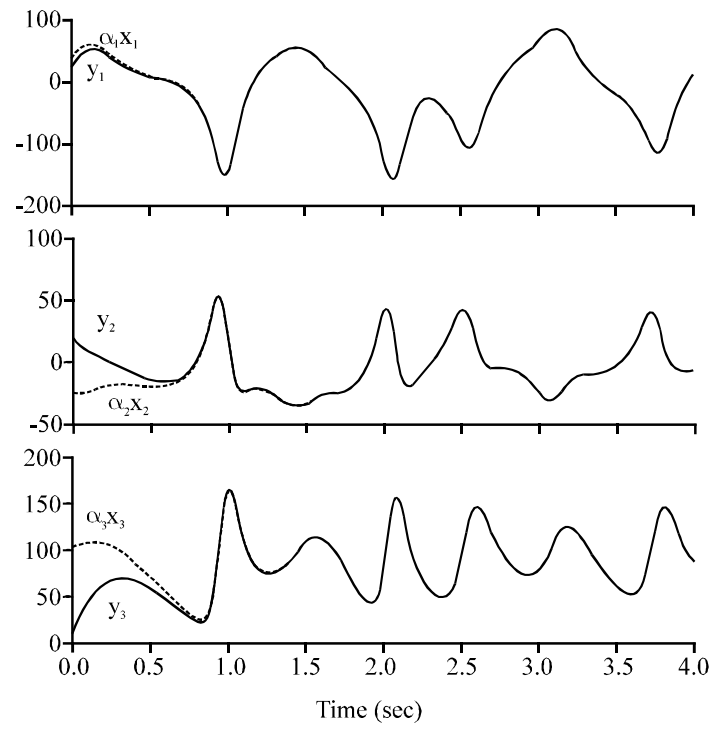

Fig. 3: GPS of the Identical Hyperchaotic Lorenz Systems

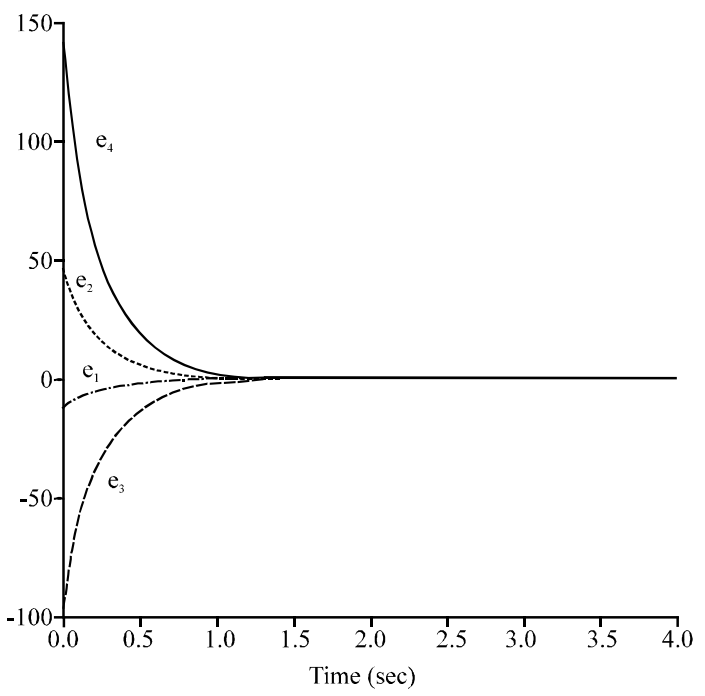

Fig. 4: Time history of the synchronization error

\section{GPS OF IDENTICAL HYPERCHAOTIC QI SYSTEMS}

Theoretical results: Researchers derive results for the Generalized Projective Synchronization (GPS) of identical Hyperchaotic Qi Systems (Chen et al., 2007). Thus, the Master System is described by the hyperchaotic Qi dynamics:

$$
\begin{aligned}
& \dot{\mathrm{x}}_{1}=\mathrm{p}\left(\mathrm{x}_{2}-\mathrm{x}_{1}\right)+\varepsilon \mathrm{x}_{2} \mathrm{x}_{3} \\
& \dot{\mathrm{x}}_{2}=\mathrm{rx}_{1}-\mathrm{sx}_{1} \mathrm{x}_{3}+\mathrm{x}_{2}+\mathrm{x}_{4} \\
& \dot{\mathrm{x}}_{3}=\mathrm{x}_{1} \mathrm{x}_{2}-\mathrm{qx}_{3}, \dot{\mathrm{x}}_{4}=-\lambda \mathrm{x}_{2}
\end{aligned}
$$

where, $\mathrm{x}_{1}-\mathrm{x}_{4}$ are the state variables and $\mathrm{p}, \mathrm{q}, \mathrm{r}, \mathrm{s}, \varepsilon, \lambda$ are constant, positive parameters of the system. Also, the 
Slave System is described by the controlled hyperchaotic Qi dynamics:

$$
\begin{aligned}
& \dot{\mathrm{y}}_{1}=\mathrm{p}\left(\mathrm{y}_{2}-\mathrm{y}_{1}\right)+\varepsilon \mathrm{y}_{2} \mathrm{y}_{3}+\mathrm{u}_{1} \\
& \dot{\mathrm{y}}_{2}=\mathrm{ry}_{1}-\mathrm{sy}_{1} \mathrm{y}_{3}+\mathrm{y}_{2}+\mathrm{y}_{4}+\mathrm{u}_{2} \\
& \dot{\mathrm{y}}_{3}=\mathrm{y}_{1} \mathrm{y}_{2}-\mathrm{qy}_{3}+\mathrm{u}_{3} \\
& \dot{\mathrm{y}}_{4}=-\lambda \mathrm{y}_{2}+\mathrm{u}_{4}
\end{aligned}
$$

Where:

$\mathrm{y}_{1}-\mathrm{y}_{4}=$ The state variables

$\mathrm{u}_{1}-\mathrm{u}_{4}=$ The active controllers of the system

For the GPS of the Hyperchaotic Systems (20) and (21), the synchronization error is defined as:

$$
e_{i}=y_{i}-\alpha_{i} x_{i},(i=1-4)
$$

where the scales $\alpha_{1}-\alpha_{4}$ are real constants. A simple calculation yields the error dynamics:

$$
\begin{aligned}
& \dot{\mathrm{e}}_{1}=\mathrm{p}\left(\mathrm{y}_{2}-\mathrm{y}_{1}\right)+\varepsilon \mathrm{y}_{2} \mathrm{y}_{3}-\alpha_{1}\left[\mathrm{p}\left(\mathrm{x}_{2}-\mathrm{x}_{1}\right)+\varepsilon \mathrm{x}_{2} \mathrm{x}_{3}\right]+\mathrm{u}_{1} \\
& \dot{\mathrm{e}}_{2}=\mathrm{ry}_{1}-\mathrm{sy}_{1} \mathrm{y}_{3}+\mathrm{y}_{2}+\mathrm{y}_{4}-\alpha_{2}\left[\mathrm{rx}_{1}-\mathrm{sx}_{1} \mathrm{x}_{3}+\mathrm{x}_{2}+\mathrm{x}_{4}\right]+\mathrm{u}_{2} \\
& \dot{\mathrm{e}}_{3}=\mathrm{y}_{1} \mathrm{y}_{2}-\mathrm{qy}_{3}-\alpha_{3}\left[\mathrm{x}_{1} \mathrm{x}_{2}-\mathrm{qx}_{3}\right]+\mathrm{u}_{3} \\
& \dot{\mathrm{e}}_{4}=-\lambda \mathrm{y}_{2}-\alpha_{4}\left[-\lambda \mathrm{x}_{2}\right]+\mathrm{u}_{4}
\end{aligned}
$$
by:

We consider the active nonlinear controller defined

$$
\begin{aligned}
& \mathrm{u}_{1}=-\mathrm{p}\left(\mathrm{y}_{2}-\mathrm{y}_{1}\right)-\varepsilon \mathrm{y}_{2} \mathrm{y}_{3}+\alpha_{1}\left[\mathrm{p}\left(\mathrm{x}_{2}-\mathrm{x}_{1}\right)+\varepsilon \mathrm{x}_{2} \mathrm{x}_{3}\right]-\mathrm{k}_{1} \mathrm{e}_{1} \\
& \mathrm{u}_{2}=-\mathrm{ry}_{1}+\mathrm{sy}_{1} \mathrm{y}_{3}-\mathrm{y}_{2}-\mathrm{y}_{4}+\alpha_{2}\left[\mathrm{rx}_{1}-\mathrm{sx}_{1} \mathrm{x}_{3}+\mathrm{x}_{2}+\mathrm{x}_{4}\right]-\mathrm{k}_{2} \mathrm{e}_{2} \\
& \mathrm{u}_{3}=-\mathrm{y}_{1} \mathrm{y}_{2}+\mathrm{qy}_{3}+\alpha_{3}\left[\mathrm{x}_{1} \mathrm{x}_{2}-\mathrm{qx}_{3}\right]-\mathrm{k}_{3} \mathrm{e}_{3} \\
& \mathrm{u}_{4}=\lambda \mathrm{y}_{2}+\alpha_{4}\left[-\lambda \mathrm{x}_{2}\right]-\mathrm{k}_{4} \mathrm{e}_{4}
\end{aligned}
$$

where the gains $k_{1}-k_{4}$ are positive constants. Substitution of (24) into (23) yields the closed-loop error dynamics:

$$
\begin{array}{ll}
\dot{\mathrm{e}}_{1}=-\mathrm{k}_{1} \mathrm{e}_{1} & , \quad \dot{\mathrm{e}}_{2}=-\mathrm{k}_{2} \mathrm{e}_{2} \\
\dot{\mathrm{e}}_{3}=-\mathrm{k}_{3} \mathrm{e}_{3} & , \quad \dot{\mathrm{e}}_{4}=-\mathrm{k}_{4} \mathrm{e}_{4}
\end{array}
$$

Theorem 2: The active controller (24) achieves Generalized Projective Synchronization (GPS) between the identical Hyperchaotic Qi Systems (20) and (21) globally and exponentially.

Proof: We prove this result using the Lyapunov Stability theory. We consider the quadratic Lyapunov function defined by:

$$
\mathrm{V}(\mathrm{e})=\frac{1}{2} \mathrm{e}^{\mathrm{T}} \mathrm{e}=\frac{1}{2}\left(\mathrm{e}_{1}^{2}+\mathrm{e}_{2}^{2}+\mathrm{e}_{3}^{2}+\mathrm{e}_{4}^{2}\right)
$$

Which is positive definite on $\mathrm{R}^{4}$. Differentiating (26) along the trajectories of the system (25), we get:

$$
\dot{\mathrm{V}}(\mathrm{e})=-\mathrm{k}_{1} \mathrm{e}_{1}^{2}-\mathrm{k}_{2} \mathrm{e}_{2}^{2}-\mathrm{k}_{3} \mathrm{e}_{3}^{2}-\mathrm{k}_{4} \mathrm{e}_{4}^{2}
$$

Which is a negative definite function on $\mathrm{R}^{4}$. Thus, by the Lyapunov Stability theory (Hahn, 1967), it follows that the error dynamics (25) is globally exponentially stable. This completes the proof.

\section{NUMERICAL RESULTS}

For the numerical simulations, the fourth-order Runge-Kutta method with time step $h=10^{-8}$ is used to solve the two systems of differential Eq. 20 and 21 with the active controller (24). The parameters of the identical Hyperchaotic Qi Systems are chosen as:

$$
\mathrm{p}=35, \mathrm{q}=4.9, \mathrm{r}=25, \mathrm{~s}=5, \varepsilon=35, \lambda=22
$$

The initial values of the Master System (20) are chosen as:

$$
x_{1}(0)=12, x_{2}(0)=7, x_{3}(0)=28, x_{4}(0)=6
$$

The initial values of the Slave System (21) are chosen as:

$$
\mathrm{y}_{1}(0)=9, \mathrm{y}_{2}(0)=17, \mathrm{y}_{3}(0)=22, \mathrm{y}_{4}(0)=18
$$

The GPS scales $\alpha_{i}$ are taken as:

$$
\alpha_{1}=-6.8, \alpha_{2}=5.6, \alpha_{3}=4.2, \alpha_{4}=-3.7
$$

We take the state feedback gains as:

$$
\mathrm{k}_{1}=4, \mathrm{k}_{2}=4, \mathrm{k}_{3}=4, \mathrm{k}_{4}=4
$$

Figure 5 shows the GPS between the identical Hyperchaotic Qi Systems (20) and (21). Figure 6 shows the time history of the error states $\mathrm{e}_{1}-\mathrm{e}_{4}$.

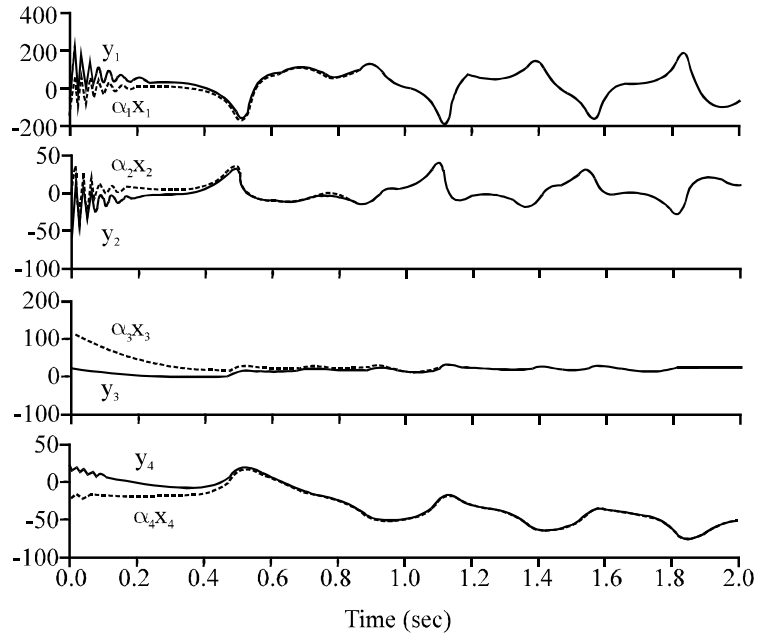

Fig. 5: GPS of the identical Hyperchaotic Qi Systems 
Int. J. Soft Comput., 6 (5-6): 216-223, 2011

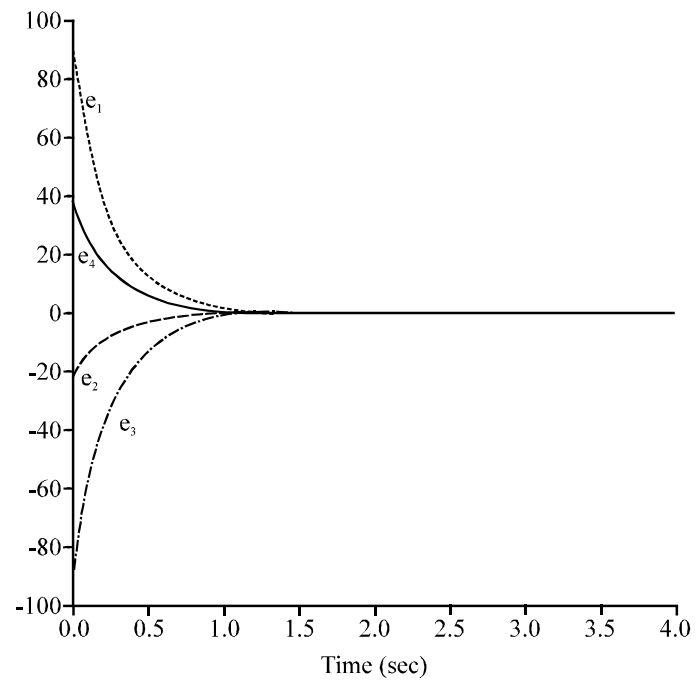

Fig. 6: Time history of the synchronization error

\section{GPS OF NON-IDENTICAL HYPERCHAOTIC LORENZ AND HYPERCHAOTIC QI SYSTEMS}

Theoretical results: Researchers derive results for the Generalized Projective Synchronization (GPS) of nonidentical hyperchaotic systems, viz., Hyperchaotic Lorenz System (Jia, 2007) and Hyperchaotic Qi System (Chen et al., 2007). Thus, the Master System is described by the Hyperchaotic Lorenz dynamics:

$$
\begin{aligned}
& \dot{\mathrm{x}}_{1}=\mathrm{a}\left(\mathrm{x}_{2}-\mathrm{x}_{1}\right)+\mathrm{x}_{4} \\
& \dot{\mathrm{x}}_{2}=-\mathrm{x}_{1} \mathrm{x}_{3}+\mathrm{cx}_{1}-\mathrm{x}_{2} \\
& \dot{\mathrm{x}}_{3}=\mathrm{x}_{1} \mathrm{x}_{2}-\mathrm{bx}_{3} \\
& \dot{\mathrm{x}}_{4}=-\mathrm{x}_{1} \mathrm{x}_{3}+\mathrm{dx}_{4}
\end{aligned}
$$

Where:

$\mathrm{x}_{1}-\mathrm{x}_{4}=$ The state variables

$\mathrm{a}-\mathrm{d}=$ Constant, positive parameters of the system

Also, the Slave System is described by the controlled Hyperchaotic Qi dynamics:

$$
\begin{aligned}
& \dot{\mathrm{y}}_{1}=\mathrm{p}\left(\mathrm{y}_{2}-\mathrm{y}_{1}\right)+\varepsilon \mathrm{y}_{2} \mathrm{y}_{3}+\mathrm{u}_{1} \\
& \dot{\mathrm{y}}_{2}=\mathrm{ry}_{1}-\mathrm{sy}_{1} \mathrm{y}_{3}+\mathrm{y}_{2}+\mathrm{y}_{4}+\mathrm{u}_{2} \\
& \dot{\mathrm{y}}_{3}=\mathrm{y}_{1} \mathrm{y}_{2}-\mathrm{qy}_{3}+\mathrm{u}_{3} \\
& \dot{\mathrm{y}}_{4}=-\lambda \mathrm{y}_{2}+\mathrm{u}_{4}
\end{aligned}
$$

where, $\mathrm{y}_{1}-\mathrm{y}_{4}$ are the state variables, $\mathrm{p}-\mathrm{s}, \varepsilon, \lambda$ are constant, positive parameters of the system and $\mathrm{u}_{1}-\mathrm{u}_{4}$ are the active controllers of the system. For the GPS of the Hyperchaotic Systems (28) and (29), the synchronization error is defined as:

$$
\mathrm{e}_{\mathrm{i}}=\mathrm{y}_{\mathrm{i}}-\alpha_{\mathrm{i}} \mathrm{x}_{\mathrm{i}},(\mathrm{i}=1-4)
$$

where the scales $\alpha_{1}-\alpha_{4}$ are real constants. A simple calculation yields the error dynamics:

$$
\begin{aligned}
\dot{\mathrm{e}}_{1}= & \mathrm{p}\left(\mathrm{y}_{2}-\mathrm{y}_{1}\right)+\mathrm{ey}_{2} \mathrm{y}_{3}- \\
& \alpha_{1}\left[\mathrm{a}\left(\mathrm{x}_{2}-\mathrm{x}_{1}\right)+\mathrm{x}_{4}\right]+\mathrm{u}_{1} \\
\dot{\mathrm{e}}_{2}= & \mathrm{ry}_{1}-\mathrm{sy}_{1} \mathrm{y}_{3}+\mathrm{y}_{2}+\mathrm{y}_{4}- \\
& \alpha_{2}\left[-\mathrm{x}_{1} \mathrm{x}_{3}+\mathrm{cx}_{1}-\mathrm{x}_{2}\right]+\mathrm{u}_{2} \\
\dot{\mathrm{e}}_{3}= & \mathrm{y}_{1} \mathrm{y}_{2}-\mathrm{qy}_{3}-\alpha_{3}\left[\mathrm{x}_{1} \mathrm{x}_{2}-\mathrm{bx}_{3}\right]+\mathrm{u}_{3} \\
\dot{\mathrm{e}}_{4}= & -\lambda \mathrm{y}_{2}-\alpha_{4}\left[-\mathrm{x}_{1} \mathrm{x}_{3}+\mathrm{dx}_{4}\right]+\mathrm{u}_{4}
\end{aligned}
$$

We consider the active nonlinear controller defined by:

$$
\begin{aligned}
\mathrm{u}_{1}= & -\mathrm{p}\left(\mathrm{y}_{2}-\mathrm{y}_{1}\right)-\mathrm{ey}_{2} \mathrm{y}_{3}+ \\
& \alpha_{1}\left[\mathrm{a}\left(\mathrm{x}_{2}-\mathrm{x}_{1}\right)+\mathrm{x}_{4}\right]-\mathrm{k}_{1} \mathrm{e}_{1} \\
\mathrm{u}_{2}= & -\mathrm{ry}_{1}+\mathrm{sy}_{1} \mathrm{y}_{3}-\mathrm{y}_{2}-\mathrm{y}_{4}+ \\
& \alpha_{2}\left[-\mathrm{x}_{1} \mathrm{x}_{3}+\mathrm{cx}_{1}-\mathrm{x}_{2}\right]-\mathrm{k}_{2} \mathrm{e}_{2} \\
\mathrm{u}_{3}= & -\mathrm{y}_{1} \mathrm{y}_{2}+\mathrm{gy}_{3}+\alpha_{3}\left[\mathrm{x}_{1} \mathrm{x}_{2}-\mathrm{bx}_{3}\right]-\mathrm{k}_{3} \mathrm{e}_{3} \\
\mathrm{u}_{4}= & \lambda \mathrm{y}_{2}+\alpha_{4}\left[-\mathrm{x}_{1} \mathrm{x}_{3}+\mathrm{dx}_{4}\right]-\mathrm{k}_{4} \mathrm{e}_{4}
\end{aligned}
$$

where the gains $k_{1}-k_{4}$ are positive constants. Substitution of (32) into (31) yields the closed-loop error dynamics:

$$
\begin{array}{ll}
\dot{\mathrm{e}}_{1}=-\mathrm{k}_{1} \mathrm{e}_{1} \quad, \quad \dot{\mathrm{e}}_{2}=-\mathrm{k}_{2} \mathrm{e}_{2} \\
\dot{\mathrm{e}}_{3}=-\mathrm{k}_{3} \mathrm{e}_{3}, & \dot{\mathrm{e}}_{4}=-\mathrm{k}_{4} \mathrm{e}_{4}
\end{array}
$$

Theorem 3: The active controller (32) achieves Generalized Projective Synchronization (GPS) between the Hyperchaotic Lorenz System (28) and the Hyperchaotic Qi System (29) globally and exponentially.

Proof: We prove this result using the Lyapunov Stability theory. We consider the Quadratic Lyapunov function defined by:

$$
\mathrm{V}(\mathrm{e})=\frac{1}{2} \mathrm{e}^{\mathrm{T}} \mathrm{e}=\frac{1}{2}\left(\mathrm{e}_{1}^{2}+\mathrm{e}_{2}^{2}+\mathrm{e}_{3}^{2}+\mathrm{e}_{4}^{2}\right)
$$

Which is positive definite on $\mathrm{R}^{4}$. Differentiating (26) along the trajectories of the system (33), we get:

$$
\dot{\mathrm{V}}(\mathrm{e})=-\mathrm{k}_{1} \mathrm{e}_{1}^{2}-\mathrm{k}_{2} \mathrm{e}_{2}^{2}-\mathrm{k}_{3} \mathrm{e}_{3}^{2}-\mathrm{k}_{4} \mathrm{e}_{4}^{2}
$$

Which is a negative definite function on $\mathrm{R}^{4}$. Thus, by the Lyapunov Stability theory (Hahn, 1967), it follows that the error dynamics (33) is globally exponentially stable. This completes the proof.

Numerical results: For the numerical simulations, the fourth-order Runge-Kutta method with time step is used 

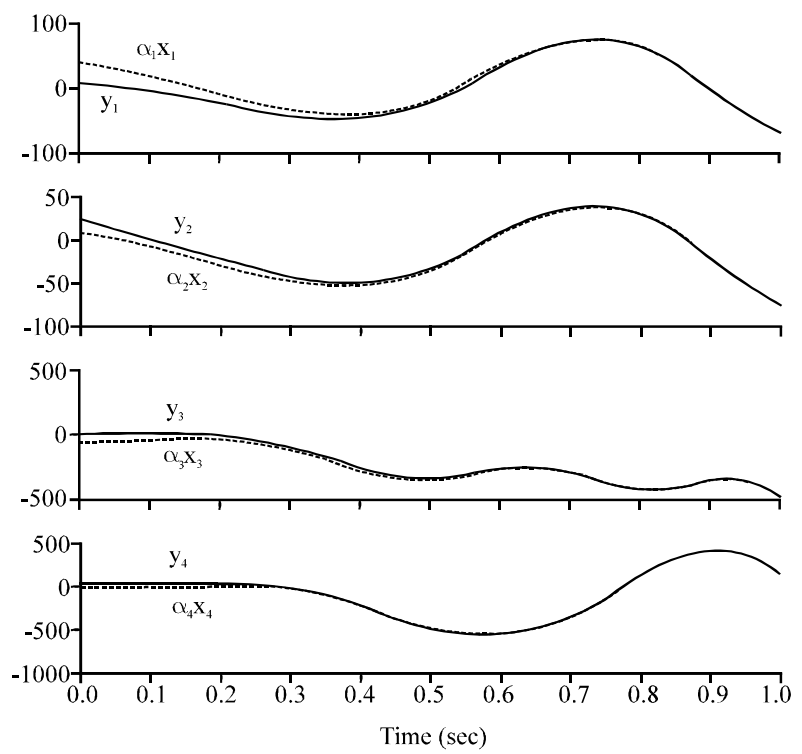

Fig. 7: GPS of the Hyperchaotic lorenz and Hyperchaotic Qi Systems

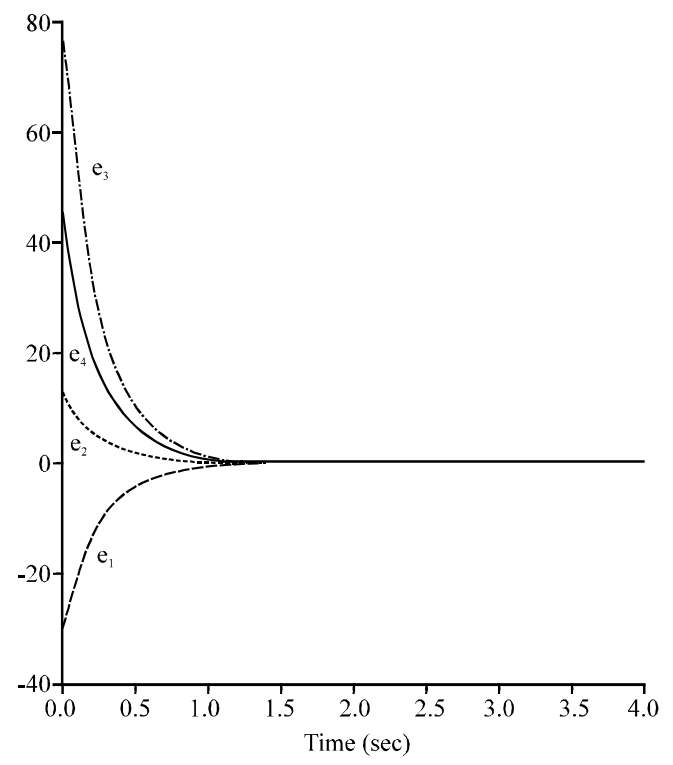

Fig. 8: Time history of the synchronization error

to solve the two systems of differential Eq. 28 and 29 with the active controller (32). The parameters of the Hyperchaotic Lorenz and Hyperchaotic Qi Systems are chosen as:

$$
\begin{gathered}
\mathrm{a}=10, \mathrm{~b}=8 / 3, \mathrm{c}=28, \mathrm{~d}=1.3 \\
\mathrm{p}=35, \mathrm{q}=4.9, \mathrm{r}=25, \mathrm{~s}=5, \varepsilon=35, \lambda=22
\end{gathered}
$$

The initial values of the master system (28) are chosen as:

$$
x_{1}(0)=15, x_{2}(0)=4, x_{3}(0)=18, x_{4}(0)=20
$$

The initial values of the Slave System (29) are chosen as:

$$
\mathrm{y}_{1}(0)=4, \mathrm{y}_{2}(0)=20, \mathrm{y}_{3}(0)=6, \mathrm{y}_{4}(0)=12
$$

The GPS scales $\alpha_{i}$ are taken as:

$$
\alpha_{1}=2.3, \alpha_{2}=1.8, \alpha_{3}=-3.9, \alpha_{4}=-1.7
$$

We take the state feedback gains as:

$$
\mathrm{k}_{1}=4, \mathrm{k}_{2}=4, \mathrm{k}_{3}=4, \mathrm{k}_{4}=4
$$

Figure 7 shows the GPS between the non-identical Hyperchaotic Lorenz System (28) and Hyperchaotic Qi System (29). Figure 8 shows the time history of the error states $\mathrm{e}_{1}-\mathrm{e}_{4}$.

\section{CONCLUSION}

In this study, researchers have deployed active control method for achieving Generalized Projective Synchronization (GPS) of the following Hyperchaotic Systems:

- Identical Hyperchaotic Lorenz Systems

- Identical Hyperchaotic Qi Systems

- Non-identical Hyperchaotic Lorenz and Hyperchaotic Qi Systems

The synchronization results (GPS) derived in this study for the Hyperchaotic Systems have been proved using the Lyapunov Stability theory.

Since, the Lyapunov exponents are not required for these calculations, the proposed Active Control Method is very effective and convenient for achieving GPS of the Hyperchaotic systems addressed in this study. Numerical simulations are shown to demonstrate the effectiveness of the synchronization results (GPS) derived in this study.

\section{REFERENCES}

Alligood, K.T., T. Sauer and J.A. Yorke, 1997. Chaos: An Introduction to Dynamical Systems. Springer, New York, USA., ISBN-13: 9780387946771, Pages: 603.

Blasius, B., A. Huppert and L. Stone, 1999. Complex dynamics and phase synchronization in spatially extended ecological system. Nature, 399: 354-359. 
Chen, S. and J. Lu, 2002. Synchronization of an uncertain unified system via adaptive control. Chaos Solitons Fractals, 14: 643-647.

Chen, Z., Y. Yang, G. Qi and Z. Yuan, 2007. A novel hyperchaos system with only one equilibrium. Phys. Lett. A, 360: 696-701.

Cuomo, K.M., A.V. Oppenheim and S.H. Strogatz, 1993. Synchronization of lorenz-based chaotic circuits with applications to communications. Inst. Electr. Electron. Eng. Trans. Circuits Syst. II, 40: 626-633.

Hahn, W., 1967. The Stability of Motion. Springer, New York, USA.

Han, S.K., C. Kerrer and Y. Kuramoto, 1995. D-phasing and bursting in coupled neural oscillators. Phys. Rev. Lett., 75: 3190-3193.

Ho, M.C. and Y.C. Hung, 2002. Synchronization of two different chaotic systems using generalized active control. Phys. Lett. A, 301: 424-428.

Jia, Q., 2007. Hyperchaos generated from the Lorenz chaotic system and its control. Phys. Lett. A, 366: 217-222.

Kocarev, L. and U. Parlitz, 1995. General approach for chaotic synchronization with application to communication. Phys. Rev. Lett., 74: 5028-5031.

Lakshmanan, M. and K. Murali, 1996. Chaos in Nonlinear Oscillators: Controlling and Synchronization. World Scientific, Singapore, ISBN-13: 9789810221430 , Pages: 325.

Lorenz, E.N., 1963. Deterministic nonperiodic flow. J. Atmos. Sci., 20: 130-141.

Mainieri, R. and J. Rehacek, 1999. Projective synchronization in three-dimensional chaotic systems. Phys. Rev. Lett., 82: 3042-3045.

Mascolo, S. and G. Grassi, 1999. Controlling chaotic dynamics using backstepping design with application to the Lorenz system and Chua's circuit. Int. J. Bifurcation Chaos, 9: 1425-1434.

Ott, E., C. Grebogi and J.A. Yorke, 1990. Controlling chaos. Phys. Rev. Lett., 64: 1196-1199.

Park, J.H. and O.M. Kwon, 2003. A novel criterion for delayed feedback control of time-delay chaotic systems. Chaos Solitons Fractals, 17: 709-716.
Pecora, L.M. and T.L. Carroll, 1990. Synchronization in chaotic systems. Phys. Rev. Lett., 64: 821-824.

Rossler, O.E., 1979. An equation for hyperchaos. Phys. Lett. A, 71: 155-157.

Sundarapandian, V., 2011b. Adaptive control and synchronization of the Shaw chaotic system. Int. J. Found. Comput. Sci. Technol., 1: 1-11.

Sundarapandian, V., 2011c. Adaptive synchronization of uncertain Sprott $\mathrm{H}$ and I chaotic systems. Int. J. Comput. Info. Sys., 2: 1-7.

Sundarapandian, V., 2011d. Anti-synchronization of Lorenz and $\mathrm{T}$ chaotic systems by active nonlinear control. Int. J. Comput. Inform. Syst., 2: 6-10.

Sundarapandian, V., 2011e. Global chaos synchronization of Shimizu-Morioka and Liu-Chen chaotic systems by active nonlinear control. Int. J. Adv. Sci. Technol., 2: $11-20$.

Sundarapandian, V., 2011a. Global chaos synchronization of liu and harb chaotic systems by active nonlinear control. Int. J. Comput. Inf. Syst., 1: 8-12.

Sundarapandian, V., 2011g. Global chaos synchronization of the Pehlivan systems by sliding mode control. Int. J. Comput. Sci. Eng., 3: 2163-2169.

Sundarapandian, V., 2011f. Hybrid synchronization of hyperchaotic rossler and hyperchaotic lorenz systems by active control. Int. J. Adv. Sci. Technol., 2: $1-10$.

Tan, X., J. Zhang and Y. Yang, 2003. Synchronizing chaotic systems using backstepping design. Chaos Solitons Fractals, 16: 37-45.

Utkin, V.I., 1977. Variable structure systems using sliding mode. IEEE Trans. Autom. Control, 22: 212-222.

Wang, Y.W. and Z.H. Guan, 2006. Generalized synchronization of continuous chaotic systems. Chaos Solitons Fractals, 27: 97-101.

Yang, T. and L.O. Chua, 1999. Control of chaos using sampled-data feedback control. Int. J. Bifurcation Chaos, 9: 215-219.

Zhou, P., F. Kuang and Y.M. Cheng, 2010. Generalized projective synchronization for fractional order chaotic systems. Chin. J. Phys., 48: 49-56. 